\title{
Autonomy in Language Education. Theory, Research and Practice: Book Review
}

\author{
Hasan Sağlamel, Berat Köse \\ Karadeniz Technical University \\ Correspondence concerning this article should be addressed to Hasan Sağlamel, Department of Western \\ Languages and Literature at Karadeniz Technical University, Kanuni Campus Trabzon, Turkey. \\ E-mail: hasansaglamel@yahoo.com
}

\section{Raya, M. J., \& Vieira, F. (Eds.). (2020). Autonomy in language education: Theory, research and practice. Routledge. Taylor \& Francis Ltd. ISBN 9780367204136}

Helping learners become self-sufficient is a great necessity, and as learner autonomy development has to do with the development of teacher autonomy (Little, 1995), the onus falls mainly on the teachers and learners themselves. What defines success cannot be reduced to simply language use and performance any longer and the incorporation of the principles of learner involvement and learner reflection call for a stronger focus on learner autonomy (see Little, 1999). Autonomy in Language Education: Theory, Research and Practice, which was edited by Manuel Jimenez Raya and Flavia Vieira, addresses the call for such focused efforts, providing a comprehensive perspective and discussion of the theoretical, historical, pedagogical, conceptual, and ideological elements of autonomy. It offers new insights into the concept of autonomy, particularly for learning, teaching, and implementing in language education.

The book consists of fourteen chapters preceded by an introduction and followed by a conclusion section. In each chapter, we can discern the echoes of Henri Holec's influential ideas regarding autonomy. The editors have arranged it under two main sections, and the first part is devoted to the historical and theoretical route of autonomy while we see research on and practical approaches of autonomy in the second part. The book starts with a list of authors who contributed to this book. In the introduction section,

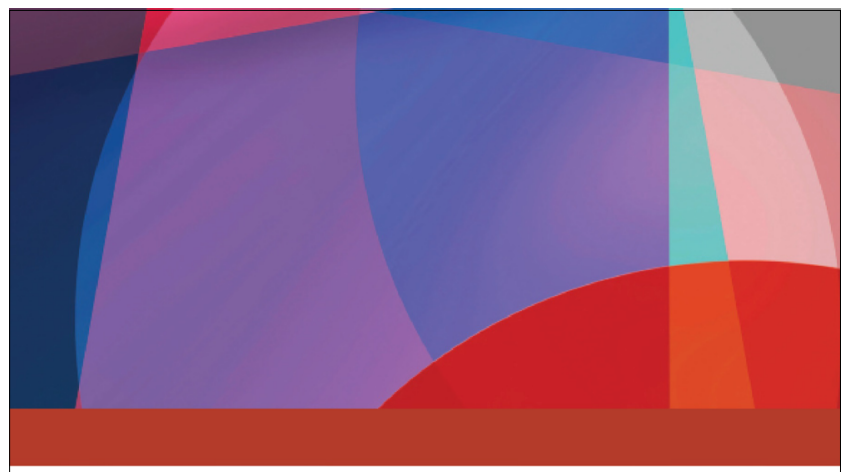

AUTONOMY IN LANGUAGE EDUCATION

THEORY, RESEARCH AND PRACTICE

Manuel Jimenez Raya and Flavia Vieira

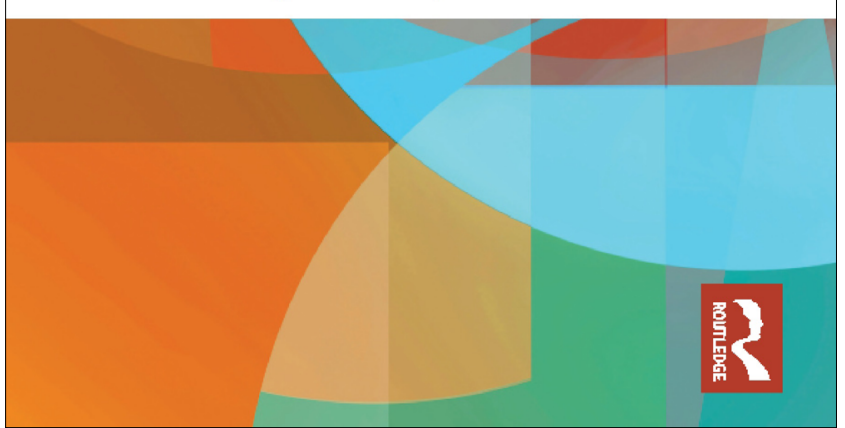
the editors inform us of the need for such a book. They also provide information about Henri Holec, who is seen as the father of autonomy, sharing some of his thoughts or statements regarding autonomy. Furthermore, the editors discuss the pedagogical perspectives toward the achievement of autonomy and come up with suggestions as to how teachers should provide their students with autonomy.

The first chapter, written by David M. Palfreyman, gives an overview of the historical context of Holec's wellknown book, Autonomy and Foreign Language Learning (AFLL). Palfreyman examines the book with reference to key terms, the themes that were associated with autonomy, the citations that were made, as well as the frequency of the employed key terms. In the second chapter, Xuesong (Andy) Gao and Jingjing Hu focus on the 
rise of self-regulation studies in language learning strategies and present a sociocultural view of language learners' self-regulated learning by displaying their own study and referring to other scholars' thoughts and research. Authored by Jo Mynard, the third chapter informs the reader from a sociocultural perspective about the origins, definitions of advising in language learning, and the significance of it for language learners. To display the most useful tools for language learning, Mynard reviews the model of advising in language learning (ALL), followed by a revised version of this model.

The fourth chapter discusses the context and the practice of learning beyond the classroom by referring to four features: location, formality, pedagogy, and control. Then Reinders presents a framework for improving learner autonomy in the language learning settings through making use of learning beyond the classroom. In the following chapter, Benson and Lamb, reflecting through dialogues, elaborate on the reasons for becoming interested in the field of autonomy and the impact of Holec's work on their ideas and teaching approaches. Moreover, the authors discuss the workability of Holec's ideas in modern times, and they regard autonomy from the perspective of multilingualism and plurilingual multicompetence. In the sixth chapter, Garold Murray presents his own opinions of learner autonomy and Holec's model from the perspective of complex dynamic systems theory. With this perspective, the author regarded certain factors that supported the emergence of autonomy: space and place, feelings and embodiment, change, and imagination. An evaluation of Holec's model and implications for further research are also made.

The second part is dedicated to the research on and practical approaches of autonomy. Vera and Junia Braga present a review of studies on autonomy in Brazilian journals. By making a review of research in the documented journals, the authors identified whether learner autonomy or teacher autonomy was more common, which definitions of autonomy were employed, which aspects of autonomy were considered, and in which way the findings are helpful for the scholars. Chapter eight, authored by Alice Chik and Silvia Melo-Pfeifer, aims to shed light on young learners' autonomy in language learning through a visual narrative approach, and the authors demonstrate the findings of a comparative study with German and Australian students who were enrolled in primary schools. The subsequent chapter is written by Leena Karlsson and Fergal Bradley, who provide information about the autonomous learning modules, referring particularly to their past, present, and personal stories. Throughout the chapter, the authors employ a biographic style that they have been using in their courses. Moreover, the authors focus on peer-groups to improve their students' autonomy, and writing from experience was viewed as a way of exploring autonomy.

The tenth chapter is concerned with the changes in self-access language learning. Through a set of interviews, Katherine Thornton demonstrated the key factors of self-access language learning. Further, the author provides information about the role of technology in self-access centres and its significance toward learner autonomy. In the following chapter, Maria Giovannna Tassinari and Jose Javier Martos Ramos inform the readers about self-access language centres, referring to previous studies and reflection of self-access practice. The authors provide a historical overview as well as the ways self-access could contribute to learners, teachers, and selfaccess language centre managers. Moreover, the authors discuss the influence of self-access language centres on learner autonomy. In the following chapter, the focus falls on pre-service teachers' views regarding the promotion of learner autonomy. Borja Manzano Vazquez focuses on pre-service teachers' perspectives toward autonomy in foreign language teaching. To this end, the author examined twenty-four pre-service teachers in terms of their willingness, ability, and opportunity to implement autonomy in their future teaching practice.

In the thirteenth chapter, Manuel Jimenez Ray discusses the role of teacher education for autonomy through the lens of the possible-selves theory, teachers' identity development, and professional identity. The last chapter, written by Flavia Viera, presents the role of inquiry in autonomy-oriented practicum settings. To offer insight about this subject, Viera examined eight student teachers' practicums. The examination provides an example of how the experiences of students in terms of pedagogical inquiry are useful for supporting learner autonomy and teacher autonomy. Lastly, the editors finish the book with concluding remarks in which they provide readers with the research viewpoints of the different authors and the implications of the studies. The editors' provision of a synthesis of research stances under three headings, namely archaeologic, review, and experience, contribute much to our understanding and the categorization of the research.

Autonomy in Language Education: Theory, Research and Practice, is a must-read book because it adds multiple voices from diverse settings, offers different methodological frameworks and provides profound implications 
for teaching and learning autonomy. For some students, relying solely on classes is not enough to learn a certain language, which makes out-of-class activities or investments a great necessity. This book presents different strategies and activities to develop learner autonomy in different settings. It also provides many frameworks from different perspectives toward learner or teacher autonomy, and resources for encouraging levels of autonomy in language education, which will be helpful for teachers to develop learner autonomy in classrooms or courses. All these make it an efficient guide for teachers hoping to help their students become more autonomous.

The book touches on the concept of autonomy in many aspects through the critical eyes of different authors. Even though the book consists of many chapters and is authored by different writers, it can be stated that the book is thoughtfully crafted, well-designed, and comprehensible. Throughout the chapters, a balanced blend of praise and criticism is presented. The healthy mix of pros and cons contributes significantly to the objectivity, enabling wiggle room for readers to make their own judgements. In addition, most of the authors clarified the reasons for utilizing autonomy in their courses and the way in which or from whom they were initially influenced in terms of autonomy. The authors also provided examples of how they employ autonomy in the language learning process. Such narratives help the authors create a dialogue with the readers.

A few suggestions could serve as room for improvement. In chapter nine, many footnotes were used. This might cause a problem for some readers as the footnotes could prove to be burdensome, even leading some to get a bit lost while reading it. Moreover, most of the chapters in this book focused on adult learners, leaving little space for young learners. Therefore, for teachers who are working at the primary stage or even in kindergartens, a greater emphasis here would be more beneficial to help promote learner autonomy in young children.

Without a doubt, as English teachers, it is our duty to prepare students and provide them with opportunities to take charge of their own learning, and this book provides foreign language teachers with many ideas for helping students become autonomous learners. Shedding light on various theories and presenting a critical view of language education, this book informs readers about potential future innovations and challenges. Thus, this book will not only be helpful and beneficial for in-service or pre-service teachers, it will also be useful for graduate students. Individuals who have an interest in the topics of education or teaching should also find it useful.

\section{References}

Little, D. (1995). Learning as dialogue: The dependence of learner autonomy on teacher autonomy. System, 23(2), 175-181. https://doi.org/10.1016/0346-251X(95)00006-6

Little, D. (1999). Developing learner autonomy in the foreign language classroom: A social-interactive view of learning and three fundamental pedagogical principles. Revista Canaria de Estudios Ingleses, 38, 77-88.

Little, D. (2007). Language learner autonomy: Some fundamental considerations revisited. Innovation in Language Learning and Teaching, 1(1), 14-29. https://doi.org/10.2167/illt040.0

Raya, M. J., \& Vieira, F. (Eds.). (2020). Autonomy in language education: Theory, research and practice. Routledge. 